\title{
Formation of Nano/Ultrafine Grains in AISI 321 Stainless Steel Using Advanced Thermo-Mechanical Process
}

\author{
Mohsen Golzar Shahri • S. Rahman Hosseini • Mehdi Salehi
}

Received: 22 August 2014/Revised: 18 October 2014/Published online: 11 February 2015

(C) The Chinese Society for Metals and Springer-Verlag Berlin Heidelberg 2015

\begin{abstract}
Production of nano/ultrafine grains through deformation-induced martensite formation and its reversion to austenite in an AISI 321 stainless steel was studied. The repetitive cold rolling and subsequent annealing were conducted to obtain nanocrystalline structure. Heavy cold rolling (90\% reduction) at +20 and $-20{ }^{\circ} \mathrm{C}$ was carried out to induce the formation of $\dot{\alpha}$-martensite from metastable austenitic material. The process was followed by annealing treatment at 700-900 ${ }^{\circ} \mathrm{C}$ for 0.5-30 min. Effects of process parameters, i.e., "reduction percentage," "rolling temperature," "annealing temperature" and "annealing time", on the microstructural development were considered. Microstructural evolutions were conducted using feritscope, X-ray diffractometer and scanning electron microscope. Hardness of the specimens was measured by Vickers method. Results revealed that the higher thickness reduction and lower rolling temperature provided more martensite volume fraction and further hardness. X-ray diffraction patterns and feritoscopic results indicated that saturated strain $\left(\varepsilon_{\mathrm{s}}\right)$ was reduced from 2.3 to 0.9 when temperature declined from +20 to $-20{ }^{\circ} \mathrm{C}$. The smallest grain size (about $70 \mathrm{~nm}$ ) was achieved in the condition of cold rolling at $-20{ }^{\circ} \mathrm{C}$ followed by annealing at $750{ }^{\circ} \mathrm{C}$ for $5 \mathrm{~min}$.
\end{abstract}

\section{KEY WORDS: Austenitic stainless steel; Deformation-induced martensite; Nano/ultrafine grain structure;} Thermo-mechanical treatment

\section{Introduction}

Austenitic stainless steels (ASSs) have many advantages from a metallurgical point of view. They can be made soft enough with yield strength about $200 \mathrm{MPa}$, but they can also be made incredibly strong by cold work up to yield strengths of over 2,000 MPa [1]. Alloy AISI 321 is a titanium-stabilized stainless steel, which offered an excellent

Available online at http://link.springer.com/journal/40195

M. G. Shahri $(\bowtie) \cdot$ M. Salehi

Department of Materials Engineering, Isfahan University

of Technology, 84156-83111 Isfahan, Iran

e-mail: m.golzar@ma.iut.ac.ir

M. G. Shahri · S. R. Hosseini

Department of Materials Engineering, Maleke-Ashtar University

of Technology, 83145-115 Isfahan, Iran resistance to intergranular corrosion. It is known that grain size is a key microstructural factor affecting physical and mechanical properties of materials [2]. Grain refinement can increase the strength as it improves toughness of the metals [3, 4]. Therefore, grain refinement has been attracting considerable leaning from material engineering science [5-7]. In recent years, there has been an interest in developing nano/ultrafine grain stainless steels to get high strength/good ductility alloys. For this purpose, several techniques including advanced thermo-mechanical treatment (ATP) and severe plastic deformation (SPD) techniques like high pressure torsion (HPT), equal channel angular pressing (ECAP) and accumulative roll bonding (ARB) have been used. Wang et al. [8] created nano/ultrafine grains in AISI 316 steel using HPT technique at room temperature followed by annealing at $500{ }^{\circ} \mathrm{C}$ for $1 \mathrm{~h}$. They attained yield strength about 2,230 MPa. Qu et al. [9] obtained bulk nanocrystalline grain structure in AISI 304L 
stainless steel by means of ECAP at room temperature. They acclaimed that two types of nanostructures were formed: nanocrystalline deformation-induced martensite (DIM) with a mean grain size of $74 \mathrm{~nm}$ and nanocrystalline austenite with a size of $31 \mathrm{~nm}$ characterized by high density of deformation twins. Reports have indicated that ASSs undergo martensitic transformation during SPD at room temperature $[9,10]$. Martensitic transformation leads to an additional grain refinement and a dual phase austenitic-martensitic nanocrystalline structure.

Tomimura et al. [11-13] have suggested a thermo-mechanical process consisting of heavy cold rolling and subsequent annealing for ASSs. They created ultrafine grains in an $\mathrm{Fe}-18 \mathrm{Cr}-8.65 \mathrm{Ni}$ alloy and two metastable ASSs $(15.6 \mathrm{Cr}-$ $9.8 \mathrm{Ni}$ and $17.6 \mathrm{Cr}-8.8 \mathrm{Ni}$ ). In addition, they investigate the mechanism of martensite to austenite phase transformation. Karimi et al. [14] produced the submicron grains in AISI 301 steel during thermo-mechanical treatment. They achieved to the smallest average austenite grain size of $(240 \pm 60) \mathrm{nm}$ with an almost fully austenitic structure. Forouzan et al. [15] achieved the nano/ultrafine grains in AISI 304L by thermomechanical treatment. Their results showed the smallest austenite grain size was obtained by annealing at $700{ }^{\circ} \mathrm{C}$ for $20 \mathrm{~min}$. Ma et al. [16] provided nanocrystalline grains of about $200 \mathrm{~nm}$ in a metastable austenitic steel by a repetitive thermo-mechanical process. This austenitic steel exhibits not only high strength (above $1 \mathrm{GPa}$ ) but also good elongation (above 30\%).

In previous investigations which used ATP, a positive $M_{\mathrm{d}}$ metastable ASS (mainly AISI 301 and 304) was processed to form nano/ultrafine structure. In other words, this process was not reported in the literatures for formation of nano/ultrafine grains in negative $M_{\mathrm{d}}$ ASS like AISI 321. Moreover, no secondary phase effect on grain growth was reported. Therefore, this work focused on the effects of ATP parameters on development of nano/ultrafine grains in AISI 321.

\section{Materials and Experimental Procedures}

Hot-rolled steel strips with $10 \mathrm{~mm}$ initial thickness were rolled using two different thickness reductions (80 and $90 \%)$ at $+20{ }^{\circ} \mathrm{C}$ room and subzero temperature $\left(-20^{\circ} \mathrm{C}\right)$. The chemical composition of AISI 321 used in this work is demonstrated in Table 1. The thickness reduction in each pass was $0.2 \mathrm{~mm}$. The specimens were cooled in methanol, salt and ice mixture $\left(-20{ }^{\circ} \mathrm{C}\right)$ before each pass of rolling.
For martensite to austenite reversion, the annealing treatments were accomplished on $90 \%$ cold-rolled steel. Annealing treatment was performed at temperatures of 700 , 750,800 and $850{ }^{\circ} \mathrm{C}$ for duration of $1,2,3,4,5,7,10,12$, 15, 20 and 30 min using an electrical furnace (Carbolite CFW1200). The specimens were subsequently quenched.

The microstructures were revealed by an optical microscope (OM, Olympus GX71) and a scanning electron microscope (SEM, COXEM CX100). The DIM and reversed austenite $(\gamma)$ were evaluated by an X-ray diffractometer $\left(\mathrm{Cu} K_{\alpha}\right.$ target, $\lambda=0.154184 \mathrm{~nm}$, focus line $0.4 \mathrm{~mm} \times 12 \mathrm{~mm}$ and exposure time $10 \mathrm{~min}$ ). Feritscope device (Fischer FMP30) was employed for DIM volume percentage measuring during the cold rolling and heat treatment processes. Hardness of the samples was measured by Vickers method (HV) using a Wilson Wolpert tester 930/250 universal hardness machine with the indenting load of $98 \mathrm{~N}$. Average results were reported after five trials.

\section{Results and Discussion}

Optical micrograph of the as-received material consisting austenite grains is shown in Fig. 1. The average grain size before cold reduction is approximately $45 \mu \mathrm{m}$ and the calculated grain size number is $G=06$, according to the ASTM E112-12 [17].

The effects of "rolling temperature" and "thickness reduction" on DIM volume percentage at both rolling temperatures are shown in Fig. 2. As can be seen, more deformation provides further DIM formation. Due to the instability of austenite in AISI 321 ASS, deformation may induce a martensitic transformation from austenite, which resulted in DIM formation. The transformation rate in the initial stage (up to $10 \%$ ) is very low because cold work energy is mostly consumed for the reduction in cross-section area. Hence, at the start of the rolling, the formation of $\alpha$-martensite is not expected, especially at room temperature. Moreover, Fig. 2 indicates that the austenite phase is completely transformed into $\alpha$-martensite phase by applying $90 \%$ and $60 \%$ thickness reduction at +20 and $-20{ }^{\circ} \mathrm{C}$, respectively. Further cold work at $-20{ }^{\circ} \mathrm{C}$ (from $60 \%$ to $90 \%$ thickness reduction) causes crushing the martensite lathes.

Based on Takaki et al. findings [11], in order to obtain nano/submicron grain structure, metastable austenite phase should be almost completely transformed to $\alpha$-martensite phase by heavy deformation. The DIM should be crushed via

Table 1 Chemical composition (wt\%) of AISI 321 stainless steel used in the present work

\begin{tabular}{llllllllll}
\hline $\mathrm{C}$ & $\mathrm{Mn}$ & $\mathrm{Si}$ & $\mathrm{Cr}$ & $\mathrm{Ni}$ & $\mathrm{Ti}$ & $\mathrm{Mo}$ & $\mathrm{S}$ & $\mathrm{P}$ & $\mathrm{Fe}$ \\
\hline 0.07 & 1.22 & 0.75 & 17.88 & 9.28 & 0.36 & 0.15 & 0.003 & 0.043 & $\mathrm{Rem}$ \\
\hline
\end{tabular}




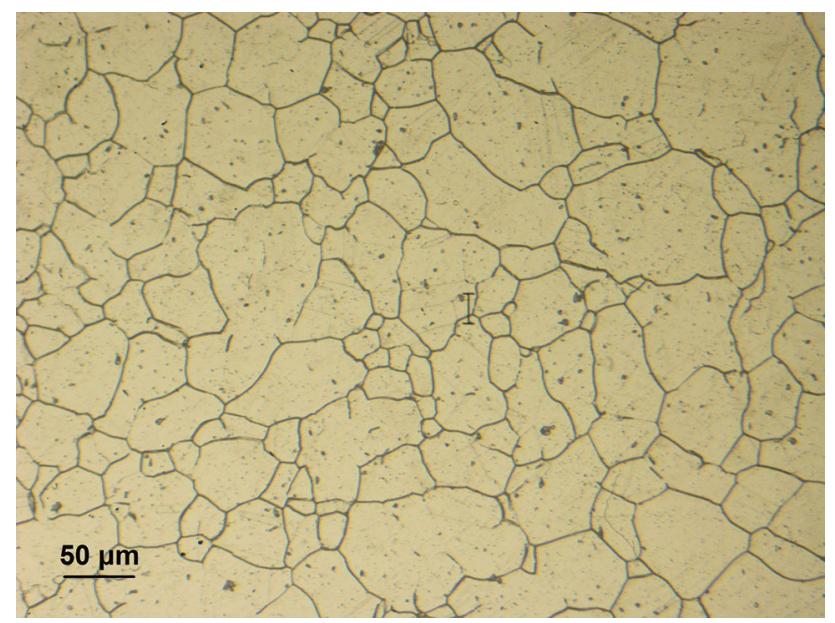

Fig. 1 Optical micrograph of as-received AISI 321 stainless steel

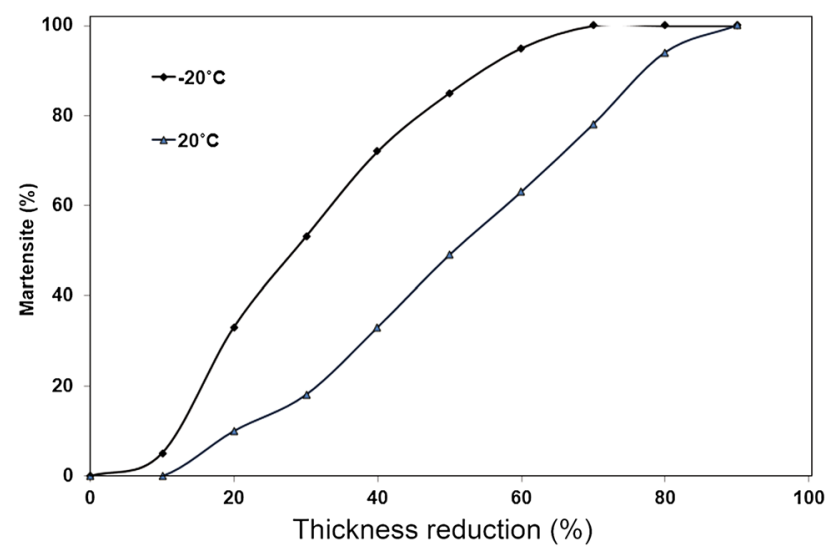

Fig. 2 Effect of rolling temperature and thickness reduction on the martensite formation during cold rolling

further deformation prior to reversion treatment. Therefore rolling at $-20{ }^{\circ} \mathrm{C}$, which leads to crush DIM after $60 \%$ thickness reduction, provides better conditions to get nano/ ultrafine grain structure. Decreasing the temperature culminates in improving the austenite to $\dot{\alpha}$-martensite transformation rate. Falling temperature causes the declining stacking fault energy (SFE) which raises the chemical driving force of the phase transformation. The SFE plays an important role in austenite stability, since it controls the formation of the shear bands and other DIM nucleation sites [16]. By increasing the temperature, SFE increases, thus nucleation sites for the $\dot{\alpha}$-martensite decrease. Therefore, the formation of $\alpha$-martensite from austenite and getting saturated strain (the strain after which austenite to martensite phase transformation will complete) will be more difficult during the plastic deformation. Saturated strain for austenite to martensite phase transformation can be calculated by [18]:

$\varepsilon_{\mathrm{s}}=\ln \frac{1}{1-r}$.

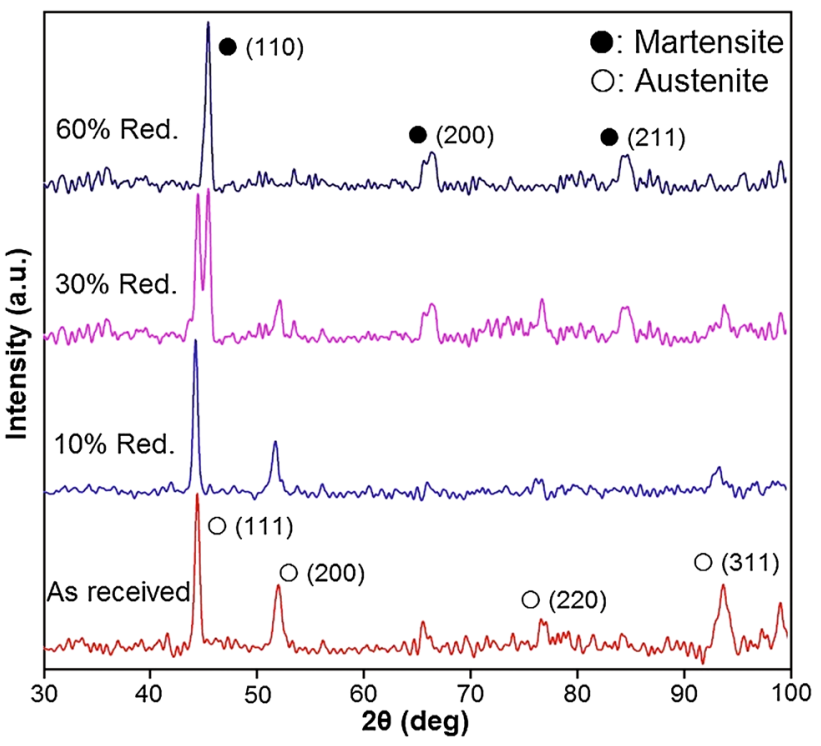

Fig. 3 XRD patterns after different cold-rolled reductions

In this equation, $\varepsilon_{\mathrm{s}}$ is the saturated strain and $r$ is the thickness reduction. Based on this equation, $\varepsilon_{\mathrm{s}}$ is calculated 2.3 and 0.9 at +20 and $-20{ }^{\circ} \mathrm{C}$, respectively.

The XRD patterns of the specimens after different reductions compared to the as-received sample are illustrated in Fig. 3. For as-received sample, austenite main peaks, related to the planes (111), (200), (220) and (311), are created in diffraction angles of $2 \theta=44.5^{\circ}, 64.5^{\circ}, 83^{\circ}$ and $95.5^{\circ}$, respectively. It is clear from as-received steel pattern that austenite is the main phase before rolling. In addition, there is no significant difference between the as-received steel and $10 \%$ reduction XRD patterns. Hence, up to $10 \%$ thickness reduction, cold work only leads to plastic deformation without significant phase transformation. After 30\% thickness reduction, the austenite main peaks, i.e., (111), (200), (220) and (311), are demonstrated. Moreover, three $\alpha$-martensite main peaks, related to the planes of (110), (200) and (211), are formed in diffraction angles of $2 \theta=43.5^{\circ}, 51^{\circ}$ and $75^{\circ}$. This fact indicates that DIM forms around 30\% deformation. In this case, $\dot{\alpha}$-martensite peaks appear with decreasing the intensity of the austenite peaks. In addition, XRD pattern for 30\% reduction demonstrates that austenite and $\dot{\alpha}$-martensite main peak intensities are approximately equal. Therefore, the volume percentages of both phases are almost equal. After $60 \%$ thickness reduction, all main peaks of $\dot{\alpha}$-martensite, i.e., (110), (200) and (211), are represented. In this pattern, austenite peaks have been eliminated and $\dot{\alpha}$-martensite became the main phase. Further cold work and rising thickness reduction only causes crushing the martensite lathes.

Both XRD patterns (Fig. 3) and feritoscopic results (Fig. 2) reveal that martensite content is about $50 \%$ after $30 \%$ thickness reduction. Thus, $M_{d}^{30}$ (the temperature at which $50 \%$ martensite will form at $30 \%$ true strain, in ${ }^{\circ} \mathrm{C}$ ) is 
estimated to be about $-20{ }^{\circ} \mathrm{C}$ (rolling temperature). These results agree fairly with Nohara et al.'s equation [19]:

$$
\begin{aligned}
M_{\mathrm{d}}^{30}= & 552-462\left(C_{\mathrm{C}}+C_{\mathrm{N}}\right)-9.2 C_{\mathrm{Si}} \\
& -8.1 C_{\mathrm{Mn}}-13.7 C_{\mathrm{Cr}}-2.9\left(C_{\mathrm{Cu}}+C_{\mathrm{Ni}}\right) \\
& -18.5 C_{\mathrm{Mo}}-68 C_{\mathrm{Nb}}-1.42(G-8),
\end{aligned}
$$

where $C$ is the content of the element as labeled in the subscript, in wt\%, $G$ is the ASTM grain size number. According to this equation, $M_{\mathrm{d}}^{30}$ is calculated about $-18^{\circ} \mathrm{C}$.

Figure 4 illustrates the hardness values versus thickness reduction at both different rolling temperatures. By increasing the thickness reduction from 0 to $90 \%$, hardness has been improved from $170 \mathrm{HV}$ to about 470 and $490 \mathrm{HV}$ for +20 and $-20{ }^{\circ} \mathrm{C}$, respectively. As it is clear, at two temperatures $\left(+20\right.$ and $\left.-20^{\circ} \mathrm{C}\right)$, hardness has a steadily upward trend as a result of martensite to austenite phase transformation. Furthermore, due to more DIM formation, measured hardness at $-20{ }^{\circ} \mathrm{C}$ is more than that of at $+20{ }^{\circ} \mathrm{C}$ in all of the rolling stages.

Figure 5 represents the effect of annealing time and temperature on the martensite percentage for $90 \%$ thickness reduction. As shown in this figure, increasing the time as well as the temperature is accompanied by reducing martensite formation. Also, higher temperature raises austenite reversion for a shorter time. This fact is likely concerned with the diffusional nucleation-growth reversion mechanism of AISI 321 [13]. The results indicate that diffusional nucleation-growth reversion occurs for a longer duration at lower temperature (i.e., $700{ }^{\circ} \mathrm{C}$ ). In other words, due to higher diffusion rate and dislocation mobility, reversion at $850{ }^{\circ} \mathrm{C}$ takes place after $2 \mathrm{~min}$, while reversion at $700{ }^{\circ} \mathrm{C}$ happens after $4 \mathrm{~min}$. At higher temperatures, dislocations slip and rearrange rapidly. Therefore, recovery occurs at a shorter time. New nuclei form and grow after the recovery, and then new nanostructural grains appear. In fact, phase transformation is completed in

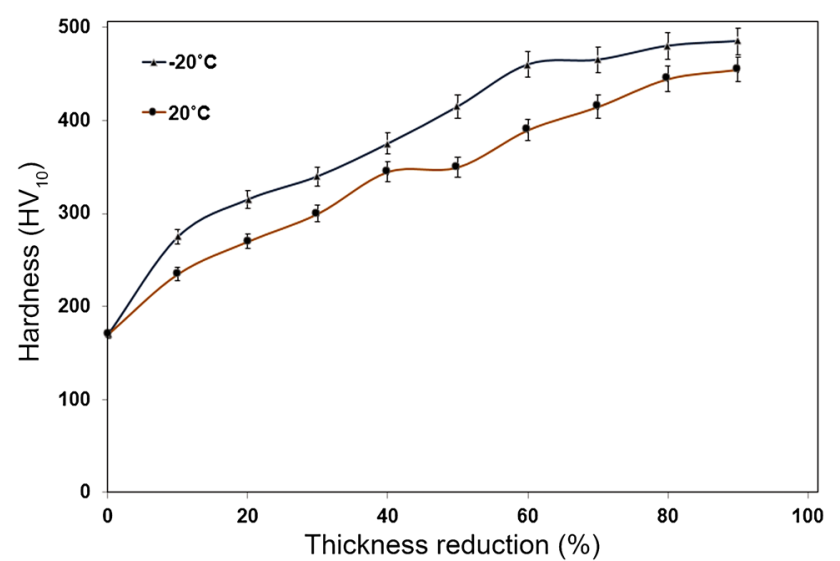

Fig. 4 Effect of rolling temperature and thickness reduction in the hardness during cold rolling

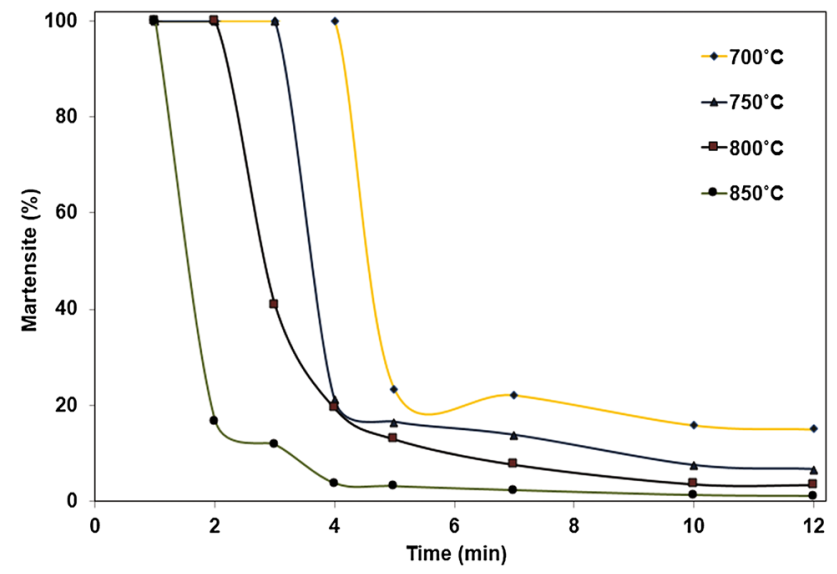

Fig. 5 Effect of annealing time and temperature on the martensite percentage after annealing

this stage and consequently grain growth is taken place. Completion of austenite reversion and grain growth affect the rising trend to reach a plateau at the end of the process (Fig. 5). However, in some cases (i.e., for $7 \mathrm{~min}$ at $700{ }^{\circ} \mathrm{C}$ ), a little deviation is observed due to the presence of titanium carbides which raises Ms above the room temperature. In case of high $\mathrm{Ms}$, having water-cooled material facilitates the martensite formation. The same phenomenon was reported in previous reports [20, 21].

The XRD patterns of the cold-rolled and annealed steels (at $800{ }^{\circ} \mathrm{C}$ ) for different times are shown in Fig. 6. Formation of $\alpha$-martensite peaks, i.e., (110), (200) and (211), before heat treatment confirms that $\dot{\alpha}$-martensite is the main phase after $90 \%$ thickness reduction. After 3 min annealing, austenite peaks, i.e., (111), (200), (220) and (311), appear and $\alpha$-martensite peak intensity decreases strongly,

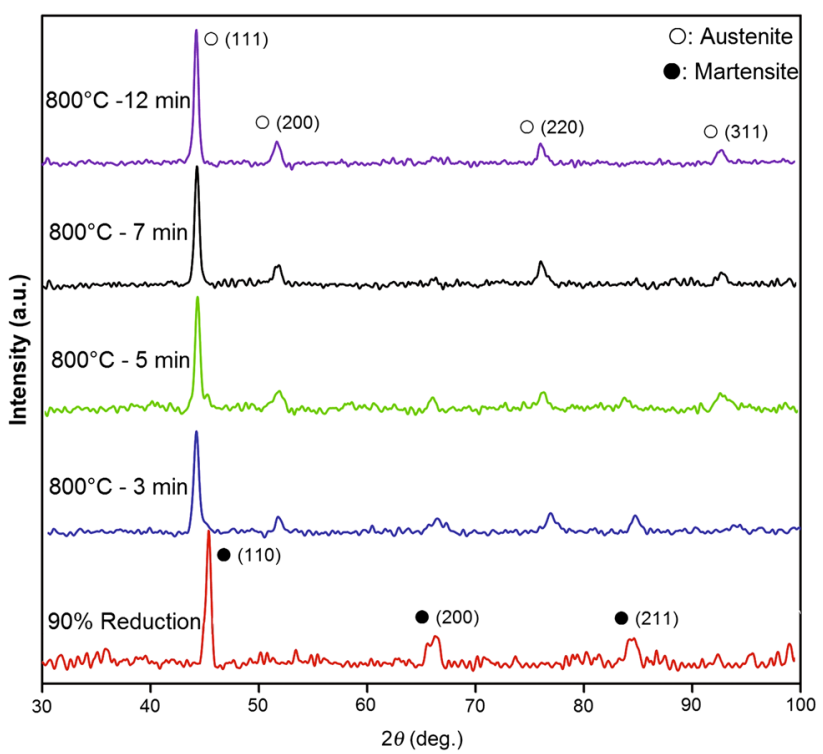

Fig. 6 XRD patterns of cold-rolled and annealed specimens at $800{ }^{\circ} \mathrm{C}$ for different annealing times 
as a result of austenite reversion. However, presence of weakened martensite peak for $5 \mathrm{~min}$ annealing is contributed to the $\alpha$-martensite existence. In contrast, elimination of $\dot{\alpha}$-martensite (200) peak and the formation of austenite (311) peak reveal that $\alpha$-martensite is completely replaced by austenite after $7 \mathrm{~min}$. After that, heat treatment only causes austenite grain growth.

Figure 7 represents the hardness as a function of annealing time and temperature for $90 \%$ deformation. As observed,

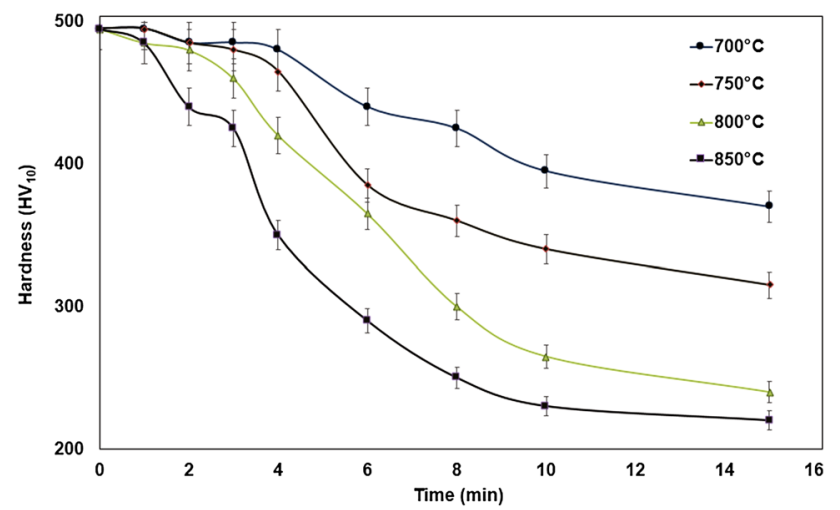

Fig. 7 Effect of annealing time and temperature on the hardness after annealing in AISI 321 stainless steel
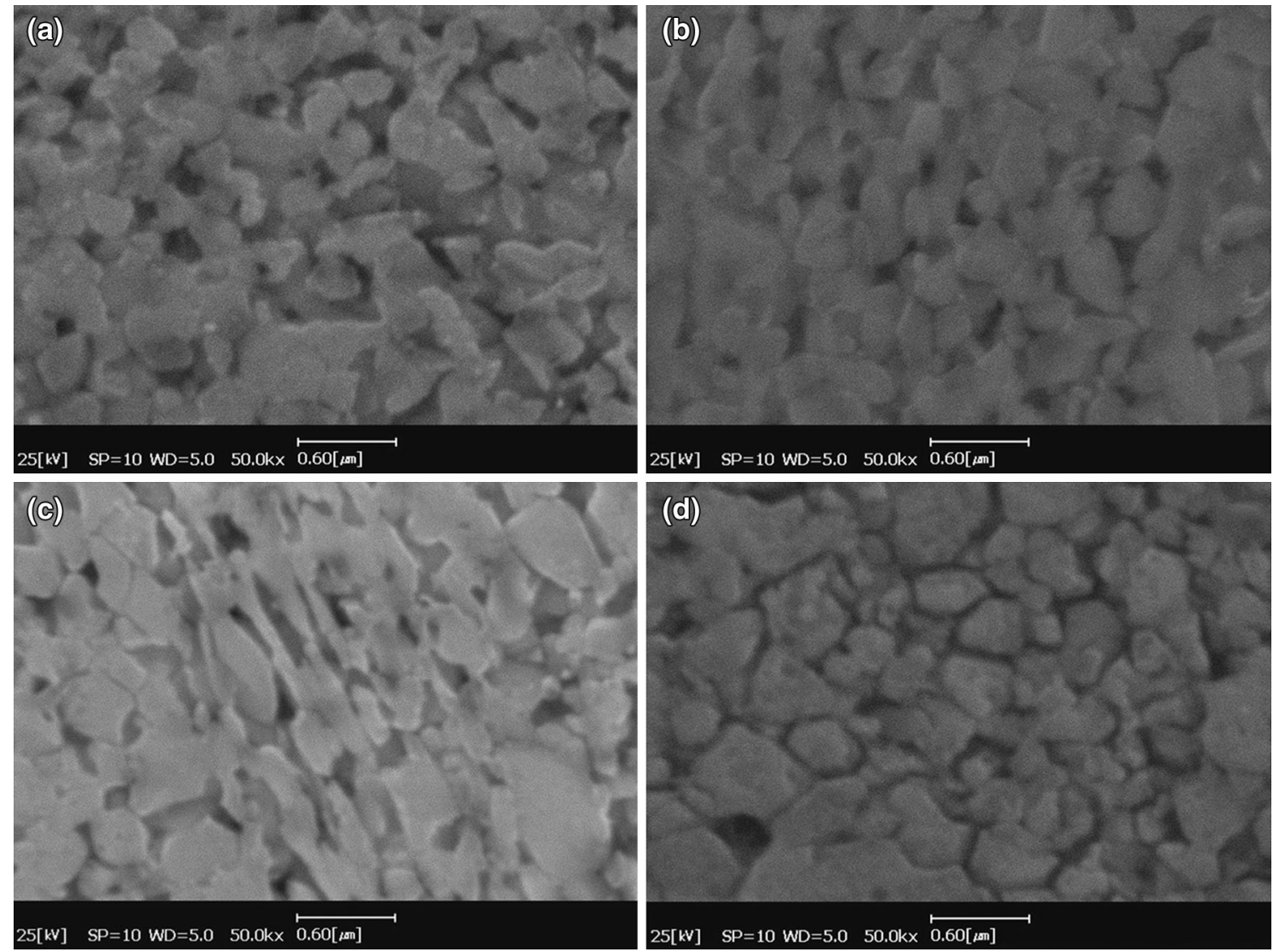

Fig. 8 SEM images of the specimens annealed at: a $750{ }^{\circ} \mathrm{C}$ for $5 \mathrm{~min}, \mathbf{b} 750{ }^{\circ} \mathrm{C}$ for $7 \mathrm{~min}, \mathbf{c} 800{ }^{\circ} \mathrm{C}$ for $5 \mathrm{~min}, \mathbf{d} 800{ }^{\circ} \mathrm{C}$ for $7 \mathrm{~min}$ 


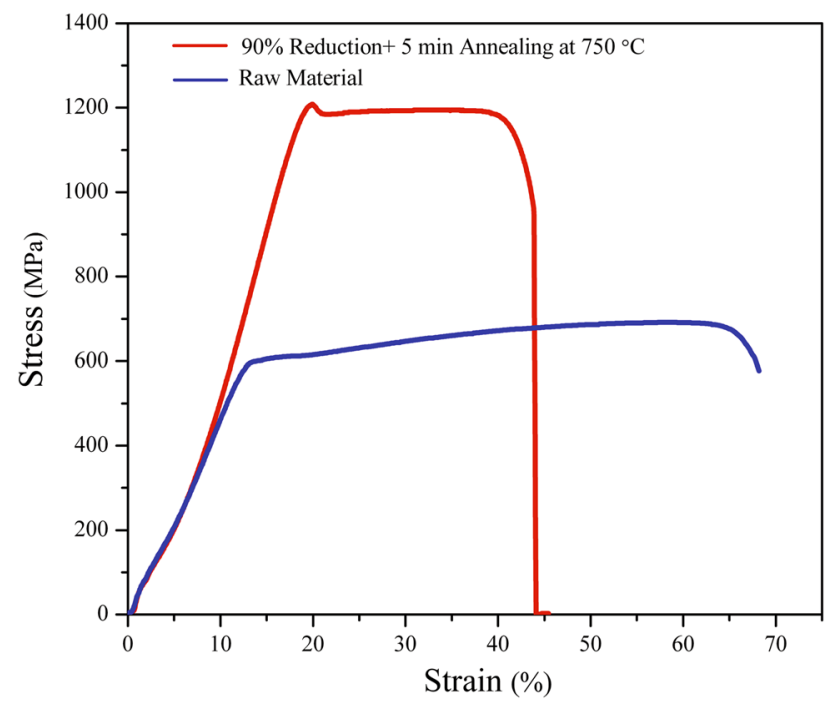

Fig. 9 Tensile properties of nanostructured steel compared to asreceived steel

$800{ }^{\circ} \mathrm{C}$ for different times. According to Takaki et al. investigations [11], the DIM should be completely reverted to austenite at temperatures or times as low as possible to suppress grain growth. These conditions exhibit smaller grains in comparison with other conditions. Figure 8a, b are the SEM micrographs of the specimens after 5 and $7 \mathrm{~min}$ annealing at $750{ }^{\circ} \mathrm{C}$. Results represent that the smallest grains with almost fully austenitic structure are achieved by annealing at $750{ }^{\circ} \mathrm{C}$ for $5 \mathrm{~min}$. The smallest grain is about $70 \mathrm{~nm}$ in diameter. The average grain size is about $130 \mathrm{~nm}$. Results indicate that the nanostructured steel (average grain size about $130 \mathrm{~nm}$ ) exhibits high strength about 1,200 MPa and good elongation compared to as-received steel (Fig. 9). Moreover, when annealing time extends, the grains will grow. In fact, grains grow easily at higher temperatures because of more dislocation mobility and higher diffusion rate. As can be seen, the average grain sizes are approximately equal for 5 and 7 min annealing at $750{ }^{\circ} \mathrm{C}$. This is due to the presence of titanium carbides in austenitic matrix that prevent the grain growth. Titanium is added to AISI 321 alloy to consume dissolved carbon and forms titanium carbide to enhance intergranular corrosion resistance [1]. Titanium carbide, as a secondary phase, also prevents the movement of grain boundaries and limits the grain growth. As a result, the average grain size is less than $400 \mathrm{~nm}$ even for $7 \mathrm{~min}$ annealing at $800{ }^{\circ} \mathrm{C}$ (see Fig. 8d).

\section{Conclusions}

(1) Advanced Thermo-mechanical process was successfully performed on AISI 321 ASS to produce an austenitic nano/ultrafine structure.
(2) During cold work, formation of $\alpha$-martensite began around $30 \%$ deformation and the metastable austenite was completely transformed to $\alpha$-martensite after $60 \%$ deformation. Decreasing the rolling temperature from +20 to $-20{ }^{\circ} \mathrm{C}$ reduced the saturated strain $\left(\varepsilon_{\mathrm{s}}\right)$ from 2.3 to 0.9 .

(3) Annealing at $750{ }^{\circ} \mathrm{C}$ for 5 min led to formation of the smallest grains (about $70 \mathrm{~nm}$ in diameter) with an almost fully austenitic structure. The average grain size in this condition is $130 \mathrm{~nm}$.

(4) Reversion mechanism in AISI 321 was diffusional nucleation-growth reversion that is annealing time dependent, unlike martensitic shear reversion that is annealing time independent.

\section{References}

[1] M. Mc Guire, Stainless Steel for Design Engineers (First Printing, ASM International, Materials Park Ohio, 2008), p. 7

[2] L. Du, S. Yao, J. Hu, H. Lan, H. Xie, G. Wang, Acta Metall. Sin. (Engl. Lett.) 27, 508 (2014)

[3] V. Kumar, I.V. Singh, B.K. Mishra, R. Jayaganthan, Acta Metall. Sin. (Engl. Lett.) 27, 359 (2014)

[4] F. Djavanroodi, A.A. Zolfaghari, M. Ebrahimi, K. Nikbin, Acta Metall. Sin. (Engl. Lett.) 27, 95 (2014)

[5] C.Z. Duan, M.J. Wang, Acta Metall. Sin. (Engl. Lett.) 26, 97 (2013)

[6] H.F. Lan, L.X. Du, N. Zhou, X.H. Liu, Acta Metall. Sin. (Engl. Lett.) 27, 19 (2014)

[7] Y.Y. Xiong, N. Li, H.W. Jiang, Z.G. Li, Z. Xu, L. Liu, Acta Metall. Sin. (Engl. Lett.) 27, 272 (2014)

[8] H. Wang, I. Shuro, M. Umemoto, H. Kuo, Y. Todaka, Mater. Sci. Eng. A 556, 906 (2012)

[9] H. Ueno, K. Kakihata, Y. Kaneko, S. Hashimoto, A. Vinogradov, J. Mater. Sci. 46, 4276 (2011)

[10] S.V. Dobat Kin, J. Zrnic, I. Mamuzik, Metalurgija 45, 313 (2006)

[11] K. Tomimura, S. Takaki, S. Tanimoto, Y. Tokunaga, ISIJ Int. 31, 721 (1991)

[12] S. Takaki, K. Tomimura, S. Ueda, ISIJ Int. 34, 522 (1994)

[13] K. Tomimura, S. Takaki, Y. Tokunaga, ISIJ Int. 31, 1431 (1991)

[14] M. Karimi, A. Najafizadeh, A. Kermanpur, M. Eskandari, Mater. Charact. 60, 1220 (2009)

[15] F. Forouzan, A. Najafizadeh, A. Kermanpur, A. Hedayati, R. Surkialiabad, Mater. Sci. Eng. A 527, 7334 (2010)

[16] Y. Ma, J. Jin, Y. Lee, Scr. Mater. 52, 1311 (2005)

[17] ASTM Standard E112-10, Standard Test Methods for Determining Average Grain Size (ASTM International, West Conshohocken, PA, 2010). doi: 10.1520/E0112-10

[18] J.E. Dieter, Mechanical Metallurgy, 3rd edn. (McGraw-Hill, New York, 1976)

[19] J.K. Nohara, Y. Ono, N. Ohashi, J. Iron Steel Inst. Jpn. 63, 212 (1977)

[20] A.F. Padilha, R.L. Plaut, P.R. Rios, ISIJ Int. 43, 135 (2003)

[21] R. Song, D. Ponge, D. Raabe, J.G. Speer, D.K. Matlock, Mater. Sci. Eng. A 441, 1 (2006) 